\title{
Metodologia para Parametrizar e Avaliar a Técnica da "Burn-zinc" no Processo de Soldagem a Ponto por Resistência
}

\section{(Methodology for Parameterize and Assessment of the Burn-Zinc technique in the Resistance Spot Welding Process)}

\author{
Vinicius Castanheira do Nascimento ${ }^{1}$, Américo Scotti ${ }^{2}$ \\ ${ }^{1}$ Air Products Brasil LTDA, Av. Francisco Matarazzo, 1400 - $11^{\circ}$ andar. Ed. Milano - Água Branca - CEP: 05001-903 São Paulo - \\ SP,nascimv1@airproducts.com \\ ${ }^{2}$ Universidade Federal de Uberlândia, Av. João Naves de Ávila, 2160 - Campus Santa Mônica - Grupo Laprosolda - Uberlândia - \\ $M G-C E P$ : 38400-902, ascotti@ufu.br.
}

\begin{abstract}
Resumo
Para minimizar os efeitos prejudiciais do zinco na soldagem a ponto por resistência de chapas galvanizadas, utiliza-se uma técnica tradicionalmente denominada "Burn-Zinc" (queima do zinco). Porém, existem poucas informações e estudos disponíveis na literatura sobre quando e como utilizá-la. O presente estudo teve a finalidade de avaliar a técnica de "burn-zinc”, procurando entender melhor o fenômeno. Para tal, foi criada uma metodologia para determinação dos parâmetros ideais para cada combinação de chapa. Uma avaliação desta metodologia foi feita com uma série de soldagens com variações sistemáticas da corrente e pressão em níveis compativeis para se obter a queima do Zn. Visualização das soldagens através de filmagem em alta velocidade, com sincronização dos sinais elétricos, foi empregada para entender os resultados. Uma vez definidos os parâmetros, soldagens foram realizadas com ou sem a aplicação da técnica. Os procedimentos experimentais propostos mostraram ser eficientes para a verificação e parametrização da técnica "burn-zinc”. Mas houve evidências que a utilização da técnica nem sempre vai ocasionar redução no tempo total de operação.
\end{abstract}

Palavras-chave: Soldagem a Ponto por Resistência, aços galvanizados, Burn-Zinc

\begin{abstract}
For minimizing the detrimental effects of zinc during resistance spot welding of galvanized sheets, a technique denominated Burn-Zinc is usually employed. However, there is no much information and studies available in the current literature about when and how to use this technique. The present work had the objective of assessing and understanding better this technique. For that, a methodology for determination of ideal burn-zing parameters as a function of the sheets was proposed. The evaluation of this methodology was carried out by a series of weldments, by systematically varying current and pressure at compatible levels for zinc burning. High speed filming, synchronized with the electrical signals, was employing for visualizing and results analyses. Once the burn-zinc parameters were defined, new weldments were done with and without the burn-zing application. The proposed experimental procedure showed to be efficient for checking and parameterization of the burn-zing technique. However, there were evidences that not always the application of the burn-zing will lead to reduction of the operational time.
\end{abstract}

Key-words: Resistance Spot Welding, galvanized steels, burn-zinc

\section{Introdução}

Chapas de aço galvanizado são bastante utilizadas na indústria automobilística por apresentarem apropriada resistência mecânica, adequada estampabilidade e satisfatória resistência à corrosão atmosférica, além de terem um custo mais baixo do que de outros materiais com propriedades mecânicas compatíveis

(Recebido em 29/07/2009; Texto Final em 26/01/2010).

Publicado com permissão da ABCM - Associação Brasileira de Engenharia e Ciências Mecânicas - Artigo originalmente apresentado no $5^{\circ}$ COBEF, Belo Horizonte, MG, Abril de 2009 com a aplicação e menor degradação corrosiva, como os aços inoxidáveis. Neste ramo industrial, a união dessas chapas é feita principalmente pelo processo de soldagem a ponto por resistência. Porém, a camada de zinco presente no revestimento (galvanização) dificulta a operação de soldagem.

Os problemas do zinco em relação à soldabilidade dos aços galvanizados por solda a ponto por resistência elétrica podem ser caracterizados por diferentes características. A primeira característica se relaciona com a metalurgia. O zinco, por si só, pode causar problemas metalúrgicos no material quando ocorre a sua fusão e formação do ponto de solda. Como ele tem baixa temperatura de evaporação e não é solúvel no aço, pode se disseminar e ocupar os espaços entre dendritas e contornos de grão nas frentes de solidificação (contornos de grãos primários), formando poros e/ou fragilizando a região e dando origem a 
trincas de solidificação. Essa fragilização ocorre na região de contato eletrodo-chapas galvanizadas, auxiliada pelo crescimento de grão das chapas devido ao calor gerado localmente e à grande capacidade de molhamento das ligas $\mathrm{Zn}-\mathrm{Cu}$ formadas. A segunda característica tem relação com a operacionalidade do processo. $\mathrm{O}$ zinco apresenta uma menor resistividade elétrica $(0,592 \mathrm{x}$ 10-8 $\Omega . \mathrm{m})$ do que a do aço $(1,590 \times 10-8 \Omega . \mathrm{m})$ [1], fazendo gerar menos calor na interface chapa-chapa. Além disso, o Zn é um metal de grande ductilidade, proporcionando maior área efetiva de contato chapa/eletrodo pelo fácil amassamento das rugosidades. Assim, a resistência elétrica é menor entre chapas galvanizadas do que entre chapas sem revestimento. Como conseqüência, é necessário utilizar correntes em maior nível para que se consiga aquecer a região de contato e formar a lente de solda. Esse aumento da corrente pode ocasionar problemas durante o processo de soldagem, como, por exemplo, um aumento excessivo da indentação na superfície pelo ponto de solda ou mesmo a ocorrência de expulsão de material na região do ponto.

Uma característica a mais é que o zinco da superfície da chapa pode difundir para o eletrodo de cobre, formando uma camada de latão na região de contato eletrodo-chapa. O latão, além de apresentar maior dureza do que o cobre, apresenta uma resistência elétrica relativamente alta e, com isso, pode provocar maior aquecimento do que desejado na região eletrodo-chapa. Como o objetivo é aquecer a região de contato chapa-chapa, o aquecimento eletrodo-chapa pode provocar indentação e/ ou expulsão e fomentar outros fenômenos não almejados. Por exemplo, o latão formado, por ter menor condutividade térmica, dificulta a refrigeração sobre a chapa e, da mesma forma, facilita a indentação no ponto [2]. Também pode ocorrer a deformação e aumento do diâmetro da ponta dos eletrodos por este aquecimento, fazendo cair a densidade de corrente (dependendo do equipamento fazendo cair a própria corrente) e comprometendo as dimensões da solda. Portanto, todos esses inconvenientes causados pela presença do zinco na camada de revestimento dificultam a soldabilidade do aço galvanizado.

O método mais comum no meio industrial para minimizar os problemas causados pela presença do zinco é através da técnica "burn-zinc" ("queima do zinco"). Esta técnica se baseia num impulso adicionado no início do ciclo total de soldagem, no qual é aplicada uma corrente mais alta do que a usada na soldagem propriamente dita por um curto período de tempo. Em teoria, esse procedimento deve fazer com que o zinco seja fundido (ou até evaporado) e, devido à pressão aplicada, expulso da região onde se formará a lente de solda, deixando um contato somente entre aço sem revestimento. Neste momento, o zinco tende a ser expulso para uma região ao redor do local onde se formará o ponto de solda, solidificando-se posteriormente. É importante ressaltar que, entre esse impulso ("burn-zinc") e o ciclo da soldagem, é indicado deixar um curto espaço tempo sem passagem de corrente. Esta técnica faz com que a resistência à passagem de corrente aumente, pois o contato se dará diretamente entre aços sem revestimento e, por conseqüência, aquecerá mais e mais rápido a região entre as chapas, formando a lente de solda de forma mais adequada.

Entretanto, a literatura científica é muito carente sobre informações mais específicas sobre esta técnica, apesar de todos os equipamentos mais modernos e de uso industrial mais produtivo ter esta função re recomendação para seu uso. Numa busca bibliográfica não se encontrou nem ao menos como se parametriza a operação. Desta forma, este trabalho apresenta a técnica "burn-zinc", propondo e avaliando uma metodologia para determinação dos parâmetros operacionais e a verificação da eficácia da técnica.

\section{Proposição de um Procedimento Padrão para Determinação dos Parâmetros para Análise da Técnica "burn-zinc"}

Com intuito de determinar parâmetros adequados para se realizar a operação de "burn-zinc" de uma dada junta a ser unida pelo processo de soldagem a ponto por resistência, foi proposto neste trabalho um procedimento padrão, através de um ensaio de simulação física. Procurou-se, com este procedimento de ensaio, achar o envelope operacional para a aplicação da técnica numa dada condição e, conseqüentemente, analisar os resultados. As etapas do procedimento são:

- Inicialmente, preparam-se corpos de prova com dimensões padronizadas $(25 \mathrm{~mm} \times 150 \mathrm{~mm}$ ) nas diferentes espessuras a serem utilizadas (ou combinação entre chapas finas e espessas). Estes valores para dimensão de chapa são subjetivos, mas foram encontrados como adequados em termos de operacionalidade e economia de material. Os corpos de prova devem ser fixados por uma das extremidades (deve-se inserir uma lâmina delgada de material não condutor entre as duas chapas na região de fixação para evitar o efeito da corrente derivativa, ou seja, o "efeito shunt". Existem outras recomendações e/ou especificações para evitar tal efeito, como fazer dois pontos em distâncias pré-estabelecidas, simulando melhor a prática, mas a primeira abordagem foi escolhida por parecer mais robusta para os propósitos);

- Aplicam-se, então, na região próxima à outra extremidade dos corpos de prova impulsos de "burn-zinc", variando-se o nível de corrente, da pressão aplicada pela pinça e do tempo de duração do impulso. Como o tempo utilizado é bastante curto, na maioria dos testes não ocorre a união entre as chapas, sendo possível separá-las manualmente e analisar a região de interesse;

- Caso ocorra a união entre as chapas em algum dos testes, fazer embutimento da amostra, cortá-la na região do ponto, atacar com um reagente próprio para o tipo de material e fazer a macrografia, para verificar se formou a lente de solda ou, caso não tenha formado, verificar se o zinco foi fundido ou deslocado para a região em torno do ponto;

- Separar as chapas e fazer uma varredura da camada de zinco na face de contato chapa-chapa (onde se iniciará a formação da lente) em uma direção linear na região onde houve ação do "burn-zinc", conforme Figura 1, com a utilização de um medidor digital de camadas (Figura 2), o qual apresenta resolução de $1 \mu \mathrm{m}$, área mínima de medição de $5 \mathrm{~mm}$ de diâmetro e acurácia de \pm 3 do valor do dígito para a faixa de interesse deste trabalho $(0$ a $100 \mu \mathrm{m})$; 


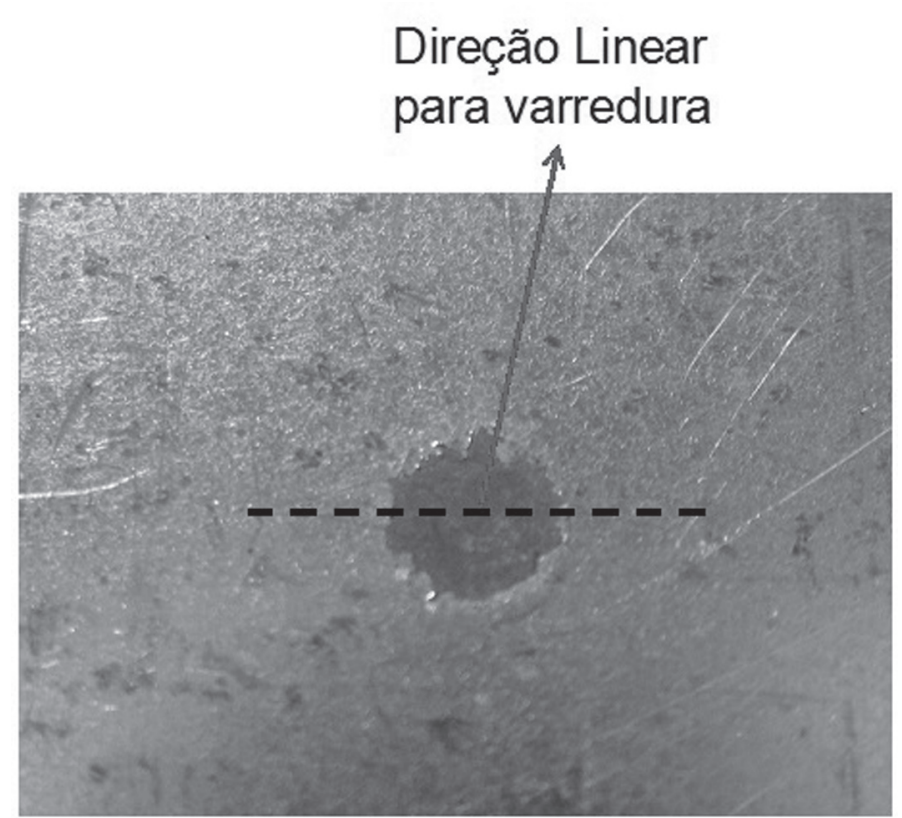

Figura 1. Direção linear para medição da camada de zinco na face de contato chapa-chapa.

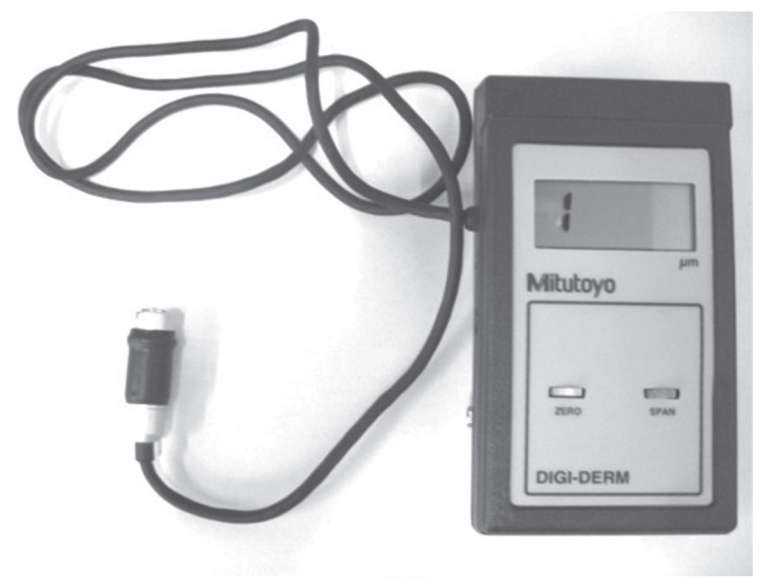

(a)

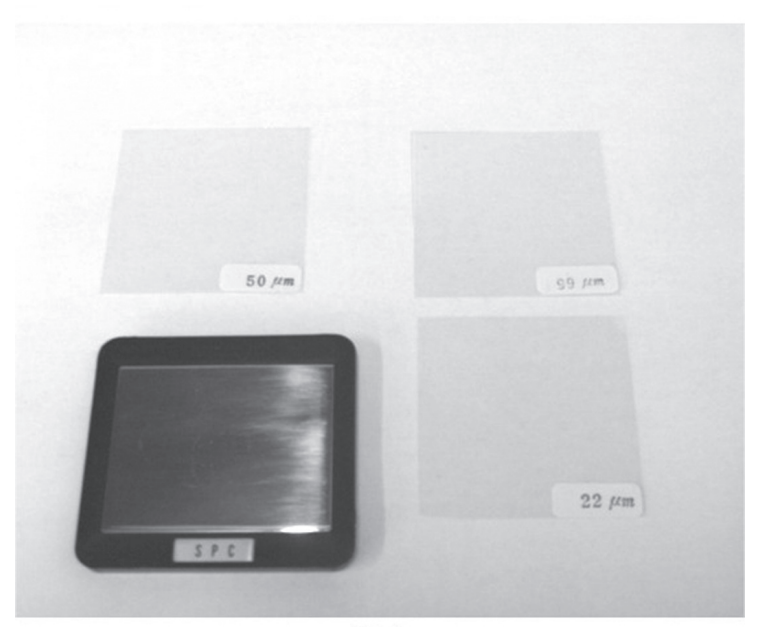

(b)

Figura 2. (a) Aparelho Mitutoyo DIGI-DERM Modelo 979745. (b) Bloco padrão e laminas de plástico para calibração

\section{Avaliação da Metodologia}

Para avaliar a metodologia proposta para encontrar o ponto de trabalho, visualizaram-se as situações de soldagens de chapas galvanizadas nas combinações 0,7-0,7 mm e 2,0-2,5 mm. As chapas utilizadas eram de galvanização a quente e a caracterização das mesmas foi feita pela espessura da camada zincada para cada espessura, medindo-se cerca de 15 pontos indiscriminadamente pela chapa, em ambos os lados, encontrando-se para a chapa de $0,7 \mathrm{~mm}$ um valor médio de $20^{ \pm 1} \mu \mathrm{m}$, para a chapa de $2,0 \mathrm{~mm}$ a espessura média de $12^{ \pm 1} \mu \mathrm{m}$, valor este que se repetiu para a chapa de 2,5 mm. Para executar a operação de um pulso para "burn-zinc", utilizou-se um equipamento de soldagem a ponto por resistência de corrente alternada em baixa freqüência (transformador Soltronic HT75 2 MF, 75 kVA, 60 Hz) e um sistema de controle tiristorizado marca Fase Saldatura, potência máxima $54 \mathrm{kVA}$. Em todos os testes ensaios foram utilizados eletrodos esféricos de Cobre Zircônio, FE16Z06, procedência Nippert - USA, classificados, segundo RWMA [3], como sendo do grupo A, classe 1.

Para cada combinação de espessuras, foi planejado uma combinação $2^{2}$ de níveis de corrente $(3,0$ e 7,0 kA) e de valor de regulagem de pressão (P1) no equipamento $(2,0$ e 6,0$)$, completado com um ponto central formado pela combinação 5,0 $\mathrm{kA}$ e $\mathrm{P} 1=3,5$, como mostra a Tabela 1 . Um tempo de 5 ciclos foi utilizado nesta fase de testes para se realizar o "burn-zinc"

Tabela 1. Parâmetros de regulagem para realizar testes de validação do procedimento (tempo de "burn-zinc" de 5 ciclos).

\begin{tabular}{|c|c|c|c|}
\hline Teste & Esp. Chapas [mm] & $\begin{array}{c}\text { Corrente } \\
{[\mathbf{k A}]}\end{array}$ & $\begin{array}{c}\text { P1(*) (Força } \\
\text { aplicada [N]) }\end{array}$ \\
\hline BZ01 & $0,7-0,7$ & 3,0 & $2,0(736)$ \\
\hline BZ02 & $0,7-0,7$ & 3,0 & $6,0(2511)$ \\
\hline$* *$ BZ03 & $0,7-0,7$ & 7,0 & $2,0(736)$ \\
\hline$* *$ BZ04 & $0,7-0,7$ & 7,0 & $6,0(2511)$ \\
\hline BZ09 & $0,7-0,7$ & 5,0 & $3,5(1403)$ \\
\hline BZ05 & $2,0-2,5$ & 3,0 & $2,0(736)$ \\
\hline BZ06 & $2,0-2,5$ & 3,0 & $6,0(2511)$ \\
\hline BZ07 & $2,0-2,5$ & 7,0 & $2,0(736)$ \\
\hline BZ08 & $2,0-2,5$ & 7,0 & $6,0(2511)$ \\
\hline BZ10 & $2,0-2,5$ & 5,0 & $3,5(1403)$ \\
\hline
\end{tabular}

* o valor P1 é adimensional, pois se trata do número de regulagem da Pressão no equipamento, mas o valor da força entre eletrodos correspondente à regulagem é apresentado entre parênteses.

** - descartada da análise, por parâmetros fora da faixa de trabalho (fusão do eletrodo na chapa)

Dos oitos testes válidos nesta fase, três deles apresentaram união entre as chapas, sendo eles o BZ01, BZ07 e BZ09. Porém, nos testes BZ01 e BZ07 esta união estava fraca ("solda fria"), soltando-se com leve esforço no sentido de abrir as chapas 
(somente o teste BZ09 apresentou uma união forte, ocorrendo a formação da lente de solda). É importante destacar que não é objetivo da técnica "burn-zinc" fazer a união de chapas e sim a queima do zinco como forma preparatória para a soldagem propriamente dita. Estas características foram confirmadas refazendo-se os três testes. Nos demais testes não ocorreram união entre as chapas, sendo possível a separação das mesmas para análise da região de interesse. Assim, as medições das espessuras da camada de zinco foram feitas utilizando-se o medidor digital de camada em ambos lados chapa-chapa dos pares de chapa de um mesmo teste.

Nota-se na Figura 3, referente ao teste BZ01, que na região central onde o ponto se formaria, o zinco foi removido em parte, mas não completamente, já que a espessura da camada do zinco na chapa original era de $19 \mu \mathrm{m}$ e após a passagem de corrente foi verificado que a espessura da camada caiu para uma faixa de 8 a $10 \mu \mathrm{m}$. Já a Figura 4, ilustrando o teste BZ02, mostra uma situação em que não ocorreu a queima do zinco; observa-se que mesmo tendo formado uma região do contato dos eletrodos (região de formação do ponto), a camada de zinco não foi removida (houve apenas uma pequena variação no valor da espessura). A Figura 5 apresenta o resultado do teste BZ03. Os parâmetros foram tão excessivos do ponto de vista de aquecimento que a chapa apresentou uma grande região com fuligem, além de que na região do ponto de solda ficou aderido o cobre do eletrodo. Como os parâmetros foram excessivos para as chapas finas, preferiu-se nem realizar o teste BZ04. Com isso, pode concluir que para as quatro combinações de parâmetros utilizados em chapas finas, não se conseguiu a queima completa do zinco ou esta foi excessiva, não sendo estes os parâmetros adequados para a técnica de "burn-zinc" neste caso.

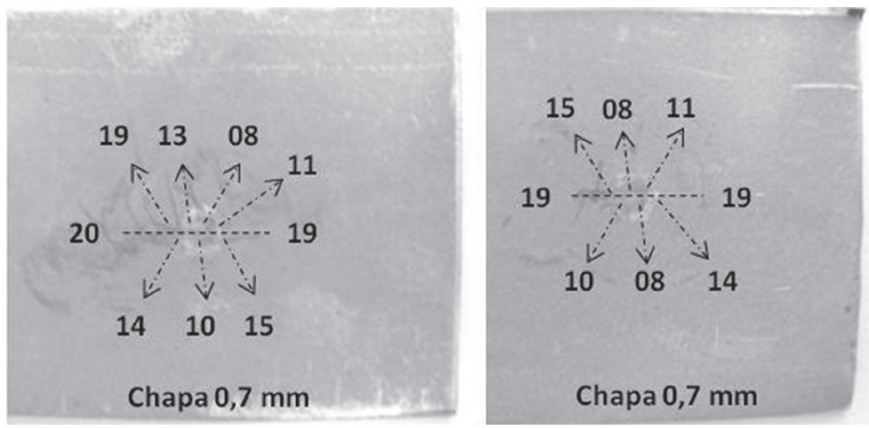

Figura 3. Espessuras da camada de zinco $[\mu \mathrm{m}]$ na região do ponto de solda do teste BZ01.
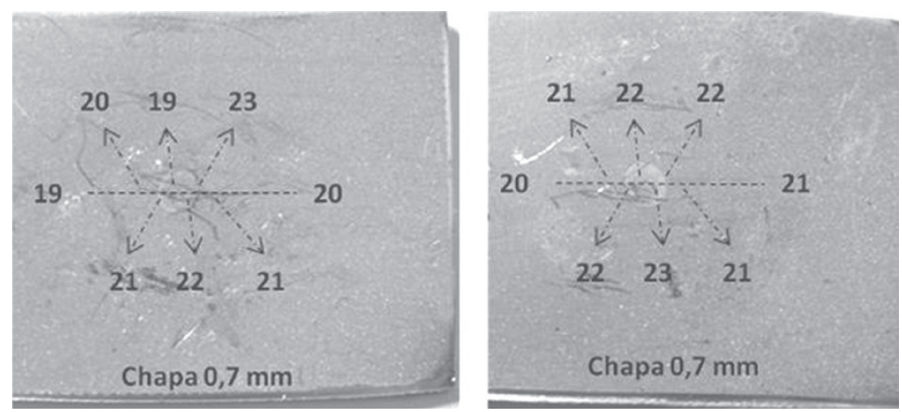

Figura 4. Espessuras da camada de zinco $[\mu \mathrm{m}]$ na região do ponto de solda do teste BZ02.

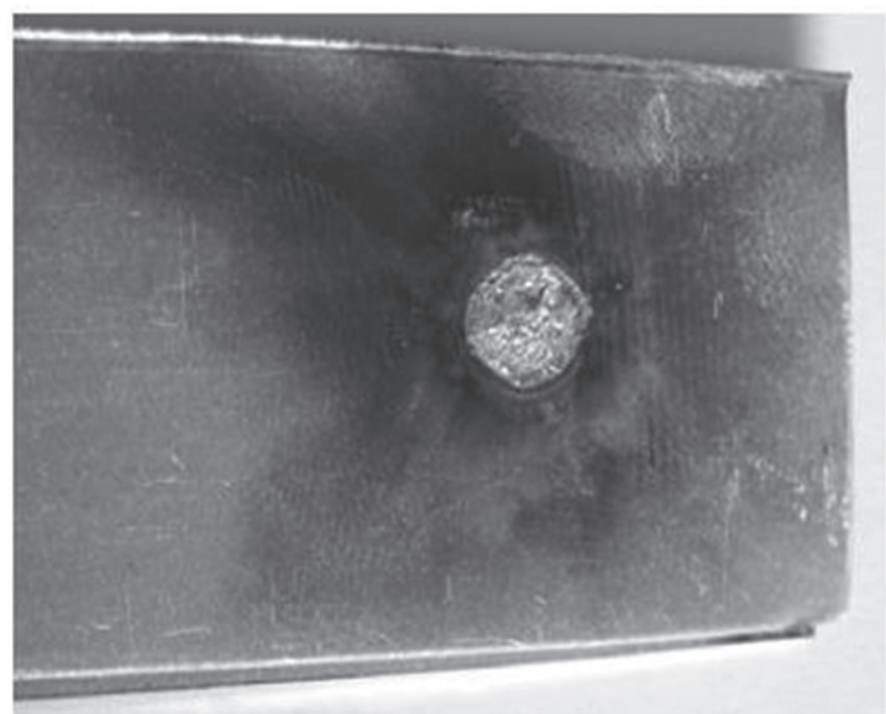

Figura 5. Parâmetros excessivos para a espessura da chapa $(0,7 \mathrm{~mm})$, teste BZ03.

Observa-se agora na Figura 6, referente ao teste BZ05, que na chapa de 2,5 mm não foi retirada qualquer camada de zinco. Pelo contrário, a camada média da chapa original era de $13 \mu \mathrm{m}$ e teve regiões que apresentaram uma camada com 21 e, até, com $23 \mu \mathrm{m}$ de espessura de zinco. Por outro lado, na outra chapa $(2,0$ $\mathrm{mm}$ ) pode ser observado que na região central onde o ponto se formaria o zinco foi retirado, ou seja, passou de uma espessura de 12 para 4 a $3 \mu \mathrm{m}$. Pode-se concluir, então, que o zinco de uma chapa passou para a outra, porém ainda permaneceu na região onde o ponto seria formado, o que não caracteriza o sucesso da técnica de "burn-zinc". A Figura 7 mostra o comportamento do teste BZ06. Percebe-se que a espessura da camada de zinco manteve-se constante em toda a região da chapa, não ocorrendo nenhuma marcação de onde os eletrodos tocavam a chapa por onde a corrente passou.

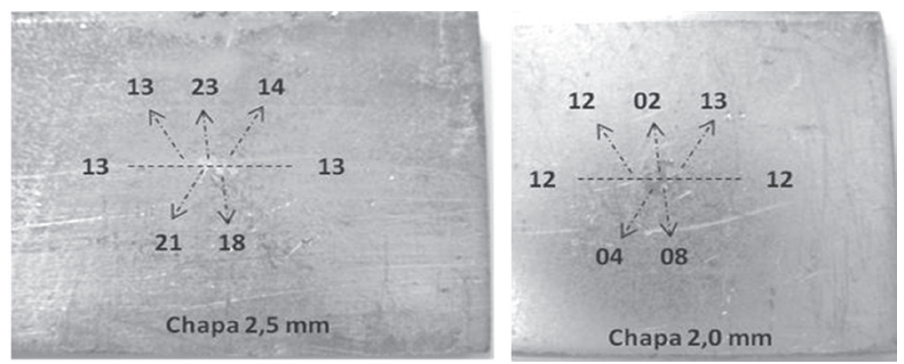

Figura 6. Espessuras da camada de zinco $[\mu \mathrm{m}]$ na região do ponto de solda do teste BZ05.

A Figura 8 apresenta o perfil da camada de zinco para o teste BZ07, onde nota-se que na região por onde se passou a corrente o zinco foi retirado; a espessura do zinco na região central caiu para uma faixa entre 1 e $4 \mu \mathrm{m}$, sendo que a espessura média na chapa de 2,5 $\mathrm{mm}$ era de $11 \mu \mathrm{m}$ e a da chapa de 2,0 $\mathrm{mm}$ de 12 $\mu \mathrm{m}$. É importante ressaltar, porém, que houve uma região onde provavelmente houve fuga da corrente (corrente derivativa região onde nota-se a retirada de zinco, porém afastada do ponto 

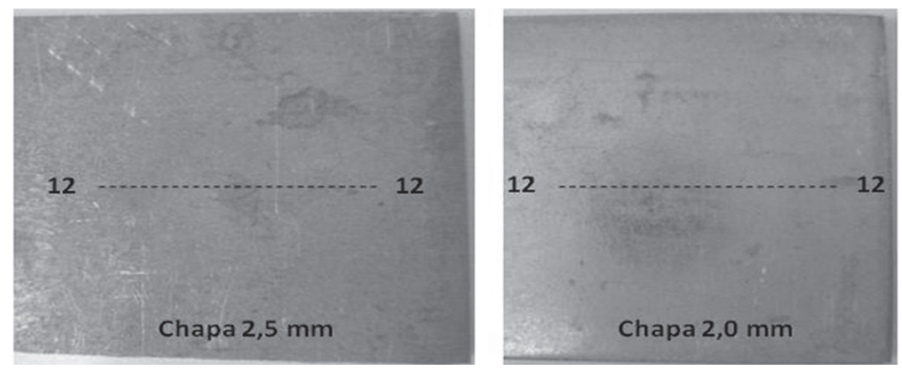

Figura 7. Teste BZ06, no qual não houve formação de ponto nem fusão de zinco.

onde se formaria a lente de solda), caracterizada pela retirada do zinco da chapa de $2,0 \mathrm{~mm}$ (faixa de 1 a $5 \mu \mathrm{m}$ ), que foi deslocada para a chapa de $2,5 \mathrm{~mm}$, onde a camada aumentou de $11 \mu \mathrm{m}$ para uma faixa de 20 a $22 \mu \mathrm{m}$. Já a Figura 9 ilustra o teste BZ08. Neste caso, observa-se que ocorreu o "burn-zinc", sendo que a espessura média da camada de zinco das chapas era de $12 \mu \mathrm{m}$ e na região central do ponto essa espessura caiu para uma faixa de 1 a $5 \mu \mathrm{m}$, o que caracteriza a queima do zinco.
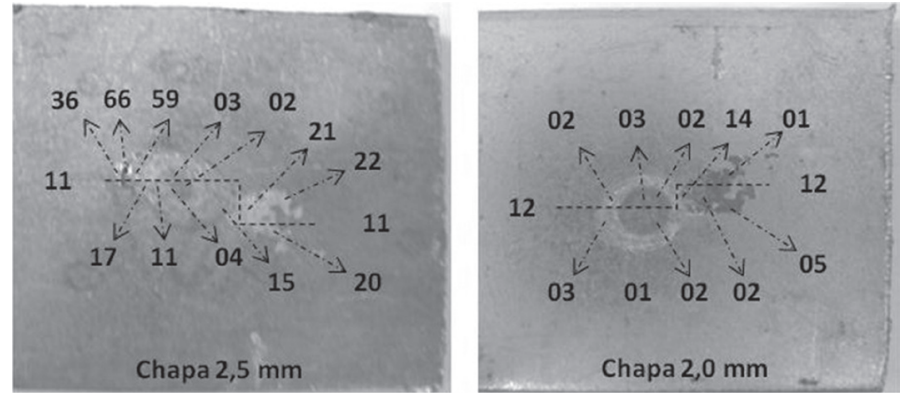

Figura 8. Espessuras da camada de zinco [ $\mu \mathrm{m}]$ na região do ponto de solda do teste BZ07.
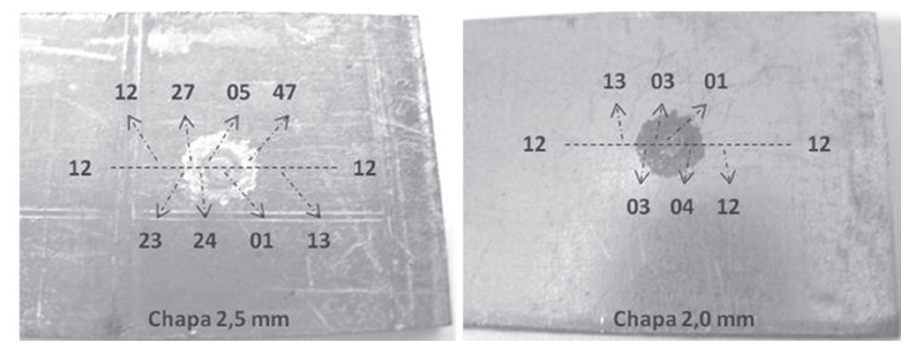

Figura 9. Espessuras da camada de zinco $[\mu \mathrm{m}]$ na região do ponto de solda do teste BZ08.

Por último, é apresentada a análise das superfícies dos últimos dois testes, com parâmetros intermediários aos dos testes anteriores $(5 \mathrm{kA}$ e P1 $=3,5)$, aplicados na combinação de chapas finas $(0,7$ com $0,7 \mathrm{~mm})$ e chapas espessas $(2,0 \mathrm{com}$ 2,5 mm). Como já mencionado, no teste BZ09 os parâmetros utilizados foram suficientes para a formação de lente de solda na chapa fina (ocorrendo a soldagem entre as chapas), não sendo possível a separação das mesmas para medição da camada de zinco. O teste BZ10, apresentado na Figura 10, por outro lado, se caracteriza pela ocorrência do "burn-zinc", ou seja, o zinco na região central do ponto foi retirado, uma vez que no centro do ponto a espessura caiu para 1 a $3 \mu \mathrm{m}$ (contra um valor médio de $12 \mu \mathrm{m}$ do revestimento da chapa em questão). É interessante observar que, na região ao redor do ponto, a camada de zinco aumentou para até $32 \mu \mathrm{m}$ (chapas de 2,5 mm), mostrando que na técnica "burn-zinc" boa parte do material do revestimento é retirado para a região ao redor do ponto de solda, deixando a região central com contato diretamente entre aço sem revestimento.
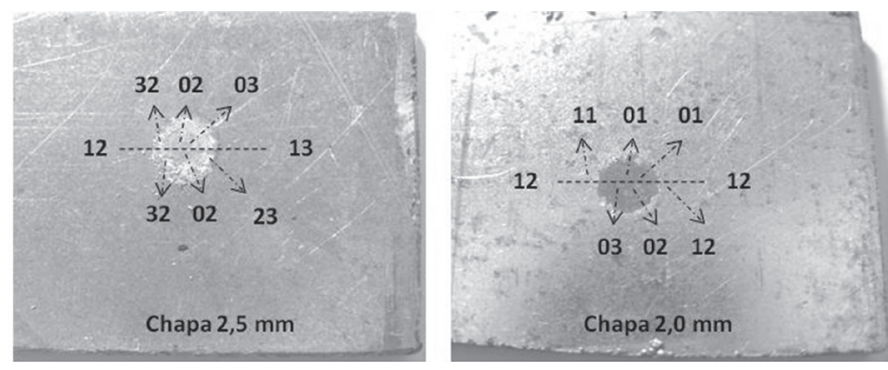

Figura 10. Espessuras da camada de zinco $[\mu \mathrm{m}]$ na região do ponto de solda do teste BZ10.

Para os três testes onde ocorreram a união entre as chapas (BZ01, BZ07 e BZ09), foram então embutidas as chapas de testes e obtidas as macrografias da seção transversal. A Figura 11 apresenta essa macrografia para o teste BZ01 (entre chapas finas), por onde se verifica que não existe nenhuma evidência de que tenha ocorrido a queima total do zinco na região onde o ponto se formaria (apesar da pouca ampliação conseguida na macrografia). Mas observa-se que na lateral esquerda de onde o ponto se formaria parece ter ocorrido uma pequena fusão de zinco, o que poderia ser a razão da "união fraca" entre as chapas, ou seja, apesar de não ter ocorrido a queima total do zinco no centro do ponto (evidenciado pela medição da camada de zinco realizada anteriormente e mostrada na Figura 3), a queima parcial do zinco pode ter sido suficiente para "colar" as chapas finas.

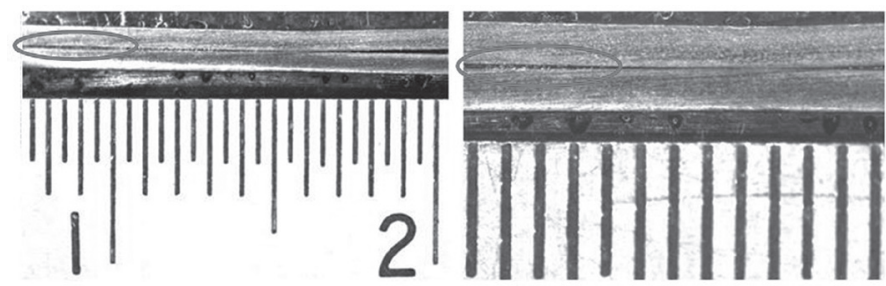

Figura 11. Seção transversal do teste BZ01 (ataque Nital 10\%).

A Figura 12 mostra o teste BZ07 entre chapas espessas. É importante ressaltar que o ataque com Nital 10\% reagiu diferentemente nas duas chapas. Nota-se que na chapa mais espessa $(2,5 \mathrm{~mm})$ o Nital atacou bastante, revelando uma região bem mais escura quando comparada ao ataque na chapa de 2,0 $\mathrm{mm}$, onde o ataque foi mais fraco. Porém, é possível observar que a lente de solda não foi formada e que existe a presença de pequenos pontos (em forma de esferas) que podem ser o zinco fundido da camada do revestimento, que no mesmo caso anterior pode ter sido a causa da união fraca entre as chapas, ou seja, o zinco fundiu e "colou" as duas chapas, porém com pouca resistência. Já a Figura 13 (teste BZ09) mostra a formação da 
lente de solda, sendo que os parâmetros utilizados no teste foram suficientes para se unir as chapas finas; neste caso a união entre as chapas foi forte (ocorreu a soldagem) e não fraca como nos dois testes anteriores.
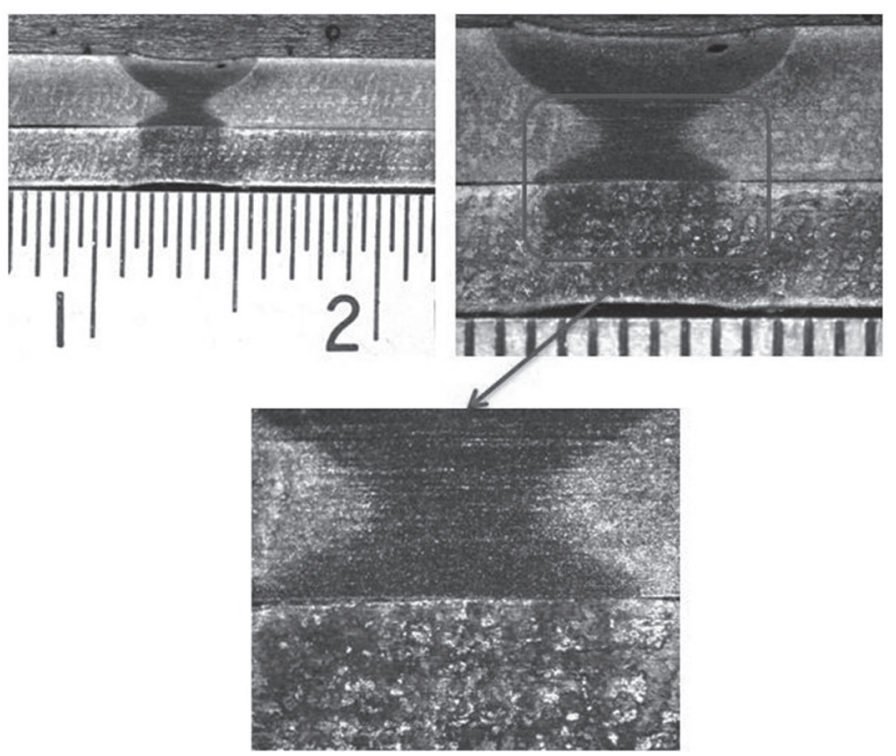

Figura 12. Seção transversal do teste BZ07 (ataque Nital 10\%).
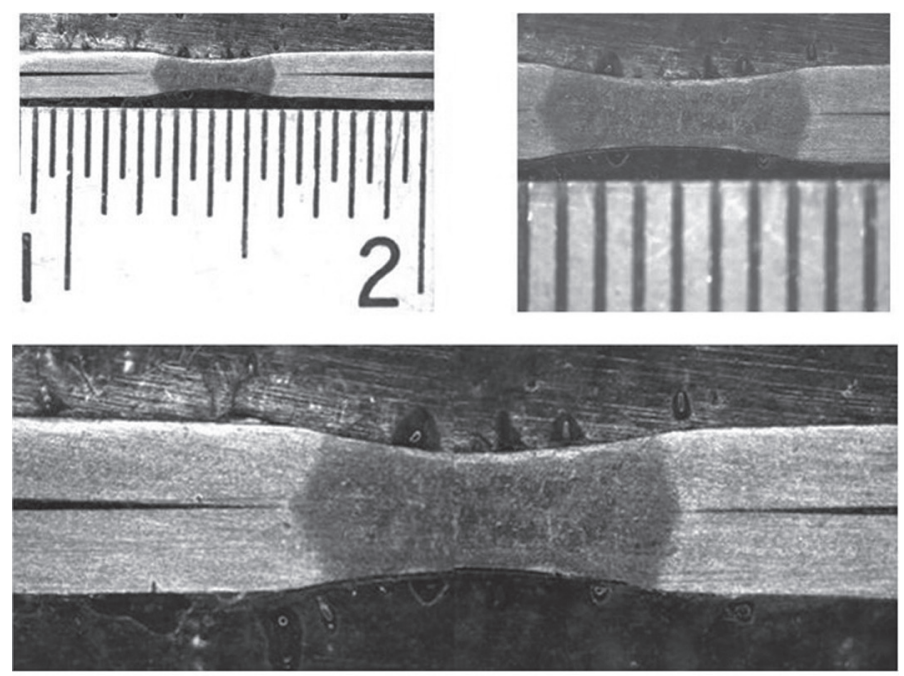

Figura 13. Teste BZ09, formação da lente de solda para efeito de comparação (Nital 10\%).

Por último, só para efeito de comparação, foi realizado mais um teste entre as chapas espessas, com os mesmos parâmetros do teste BZ07, porém com um tempo maior (15 ciclos). Observa-se na Figura 14 que, mesmo o ataque atuando de maneira diferente nas duas chapas, formou-se o ponto de solda. Além disto, na lateral esquerda do ponto de solda apareceu um metal fundido (provavelmente zinco que foi expulso para a região em torno do ponto).

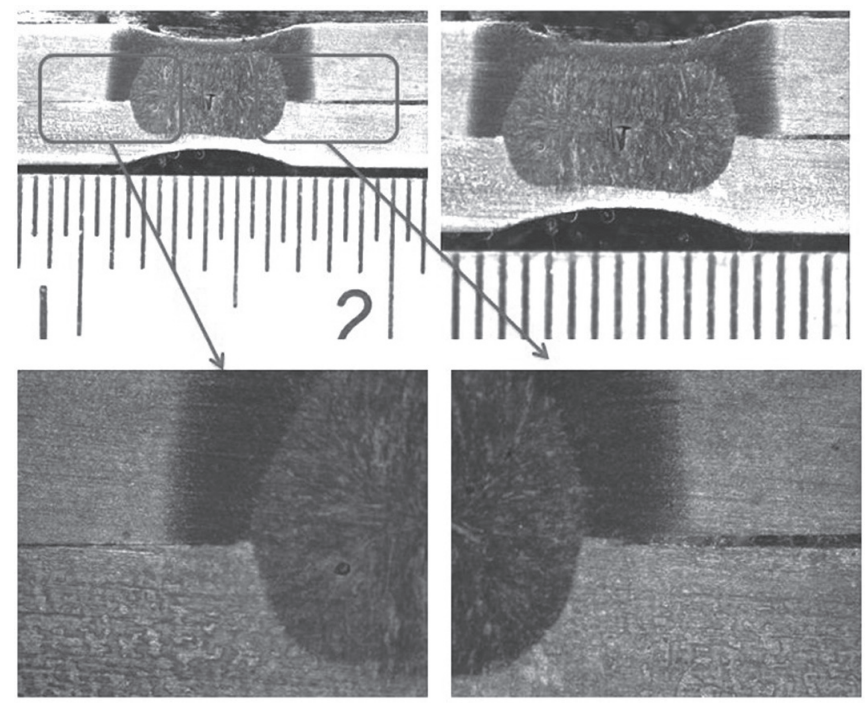

Figura 14. Seção transversal da lente de solda para união de chapa de 2,5 $\mathrm{mm}$ com 2,0 $\mathrm{mm}$, utilizando parâmetros reais de soldagem, para efeito de comparação (teste BZ07).

Observa-se na macrografia da Figura 12 a presença de um grande poro próximo à superfície da chapa superior. Notase, também, que na Figura 14 existe um vazio (em forma de T) bem na região central da lente de solda e alguns pequenos poros na região lateral da lente formada. Esse comportamento pode ser explicado devido ao zinco que foi evaporado durante a operação e ficou aprisionado no interior do material ou ainda na reação química durante o ataque do Nital para a revelação da macrografia; o zinco poderia ter sido atacado fortemente sendo retirado da região, permanecendo somente o vazio. Porém, não é o objetivo do presente trabalho analisar estas descontinuidades ou defeitos.

Assim, utilizando o procedimento proposto e avaliado, tornou-se possível identificar o envelope operacional (tempo, corrente e pressão) para se conseguir "burn-zinc" que realmente conseguem retirar a camada para cada tipo de combinação de material. Para visualizar e confirmar os resultados acima, procurou-se filmar o ponto de união das chapas sob impulsos para "burn-zinc", utilizando-se uma câmera de alta velocidade com imagens sincronizadas com sinais de tensão e corrente. Para tal os eletrodos foram truncados (a ponta foi usinada ao meio, conforme detalhado em Vilarinho et al [4], e o ponto de solda realizado na aresta da extremidade das chapas, para que fosse possível a sua visualização. Com a filmagem, a análise é mais completa, pois se pode ver quadro a quadro a formação do fenômeno e ainda fazer uma comparação com a corrente e a tensão. Pela Figura 15, referente a uma condição de corrente baixa (3 kA) e regulagem de pressão alta $(\mathrm{P} 1=6,0)$, verifica-se que não ocorreu a expulsão e nem evaporação de zinco, sendo os parâmetros impróprios para a esta combinação de espessuras de chapas (2,0 com 2,5 mm). Observa-se no oscilograma que foi utilizado um tempo de cinco ciclos, porém a corrente não teve um valor suficiente para que ocorresse o "burn-zinc". É também importante ficar atento ao fato da tensão praticamente não se alterar durante todo o tempo de passagem de corrente, sugerindo não haver mudança na resistência de contato. 

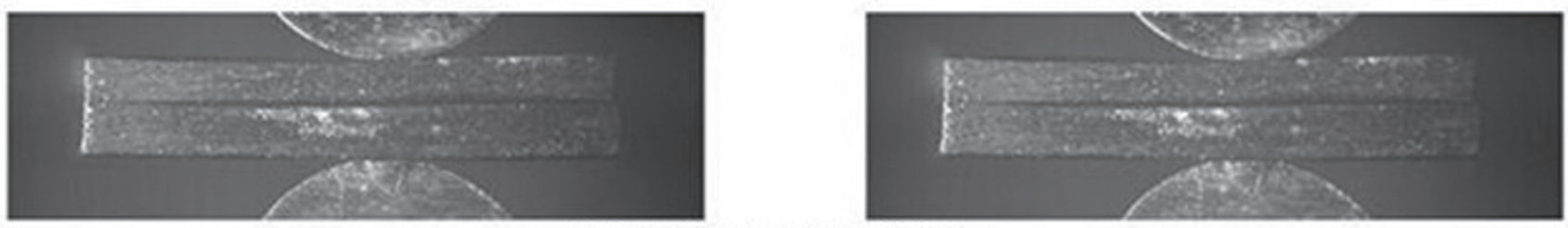

\section{LAPROSOLDA-UFU}
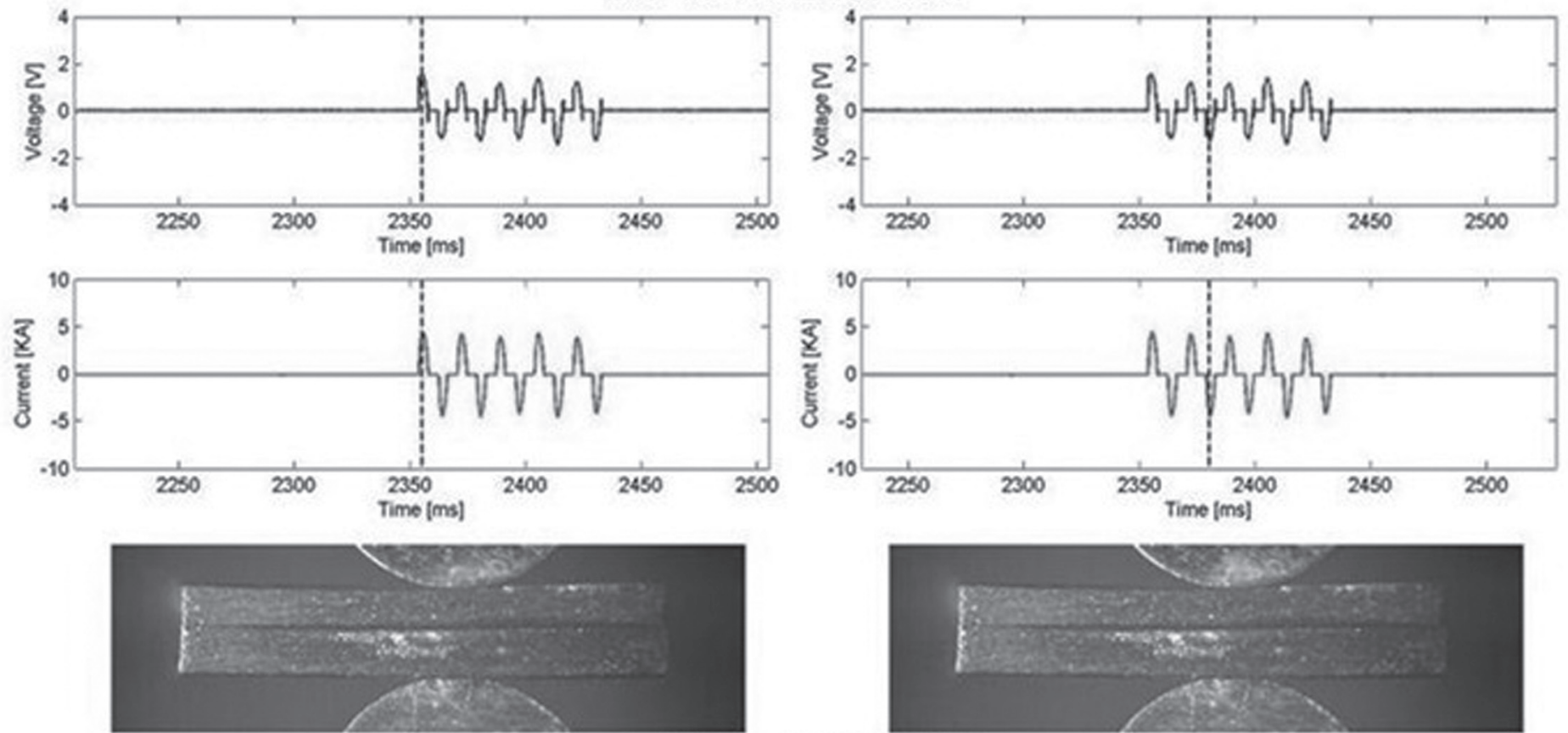

LAPROSOLDA-UFU
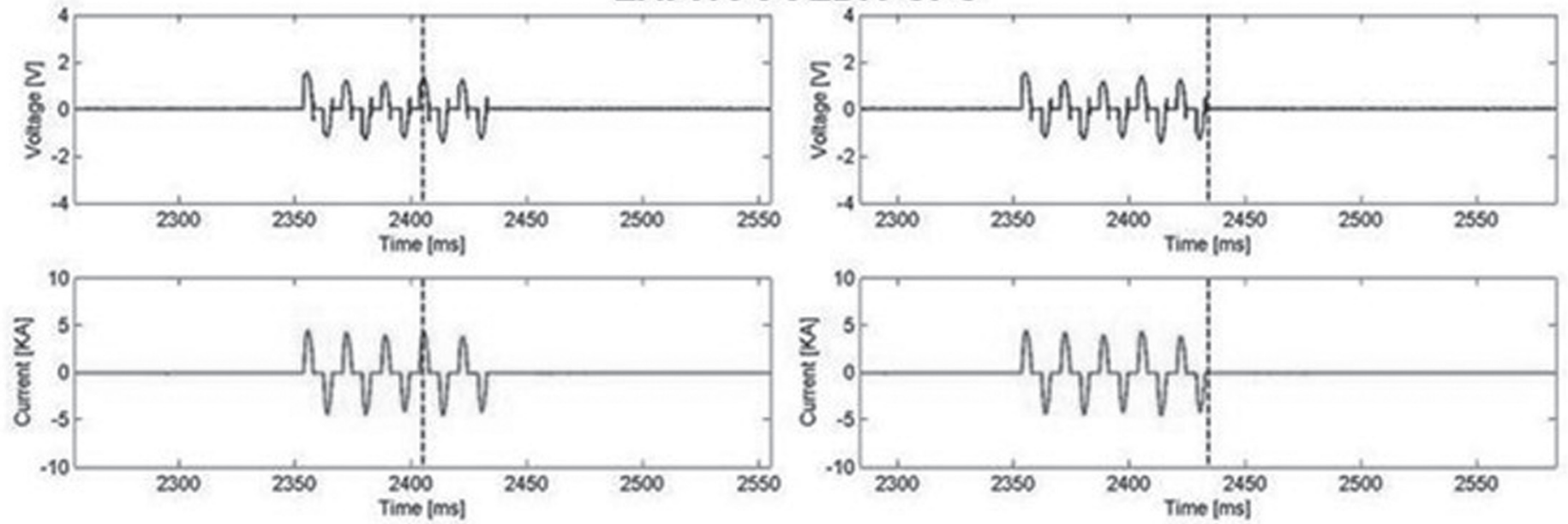

Figura 15. Quadros seqüenciais ilustrando o comportamento da interface chapa-chapa durante a aplicação da técnica "burn-zinc" por 5 ciclos, mas com parâmetros (corrente e/ou pressão) insuficientes para se obter a queima do revestimento (teste BZ06, realizado com uma corrente de $3 \mathrm{kA}$ com uma regulagem de pressão $\mathrm{P} 1=6,0 \mathrm{em}$ chapas 2,0-2,5 mm).

A Figura 16, referente a uma combinação de corrente e regulagem intermediárias ( $5 \mathrm{kA}$ e $\mathrm{P} 1=3,5$, também por 5 ciclos) para as chapas 2,0-2,5 mm, mostra, por outro lado, a ocorrência com sucesso da técnica de "burn-zinc". Já nos primeiros ciclos ocorre um aquecimento na região de contato chapa-chapa. Ao passar do tempo, o material da chapa na região entre os eletrodos aquece bastante, sofrendo alterações metalúrgicas. É interessante observar que depois de um curto tempo após o final da passagem de corrente, surge uma fumaça esbranquiçada saindo do interior da região de contato chapa-chapa, caracterizando a evaporação do zinco presente na região. Percebe-se também que a tensão aumenta até o terceiro ciclo, sugerindo que a resistência de contato está aumentando coerentemente. 

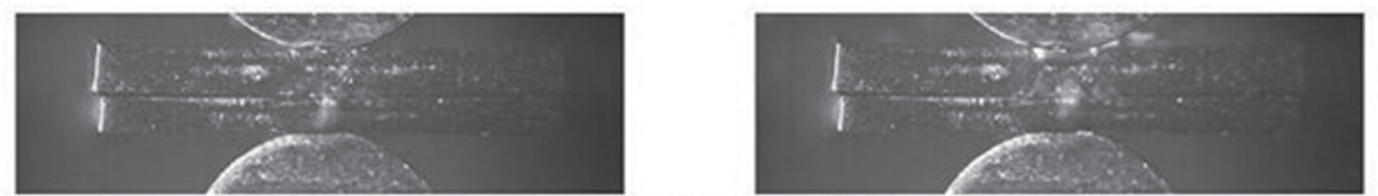

\section{LAPROSOLDA-UFU}
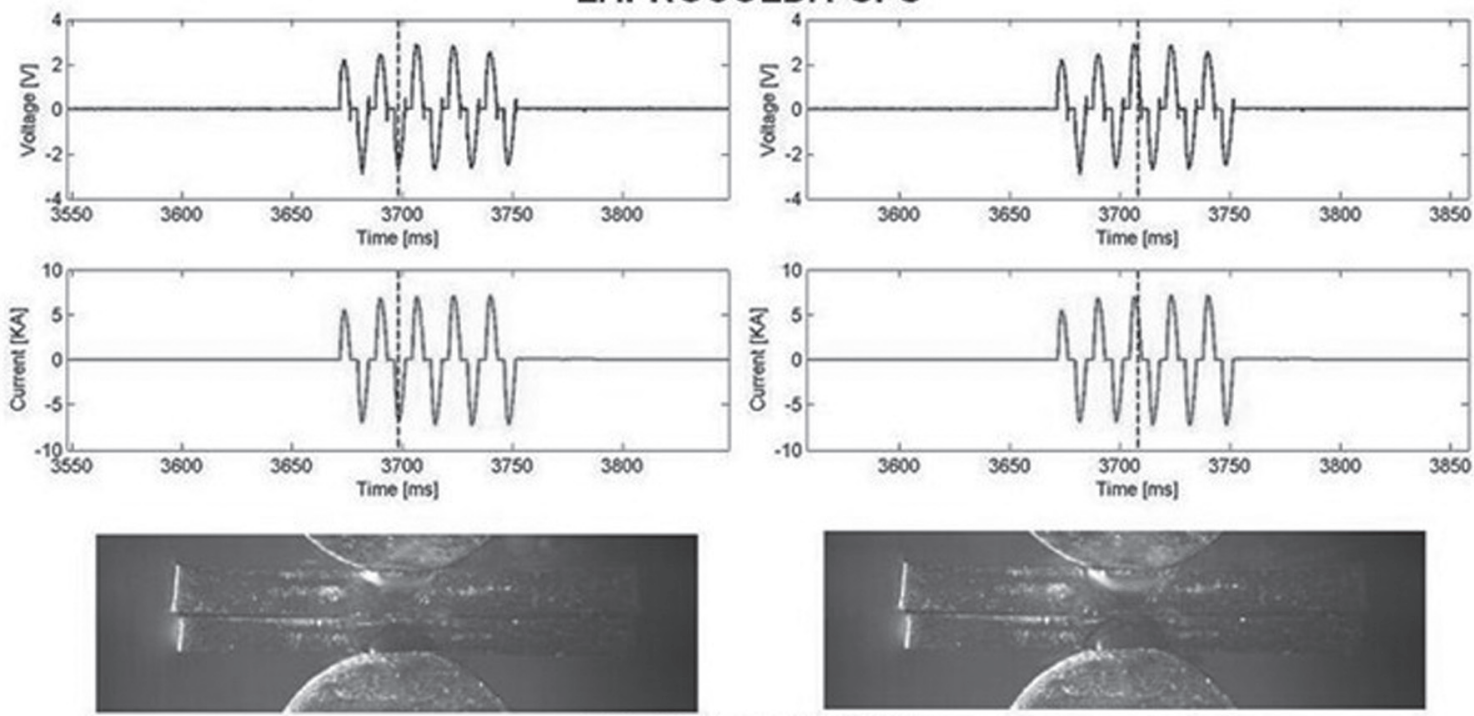

\section{LAPROSOLDA-UFU}
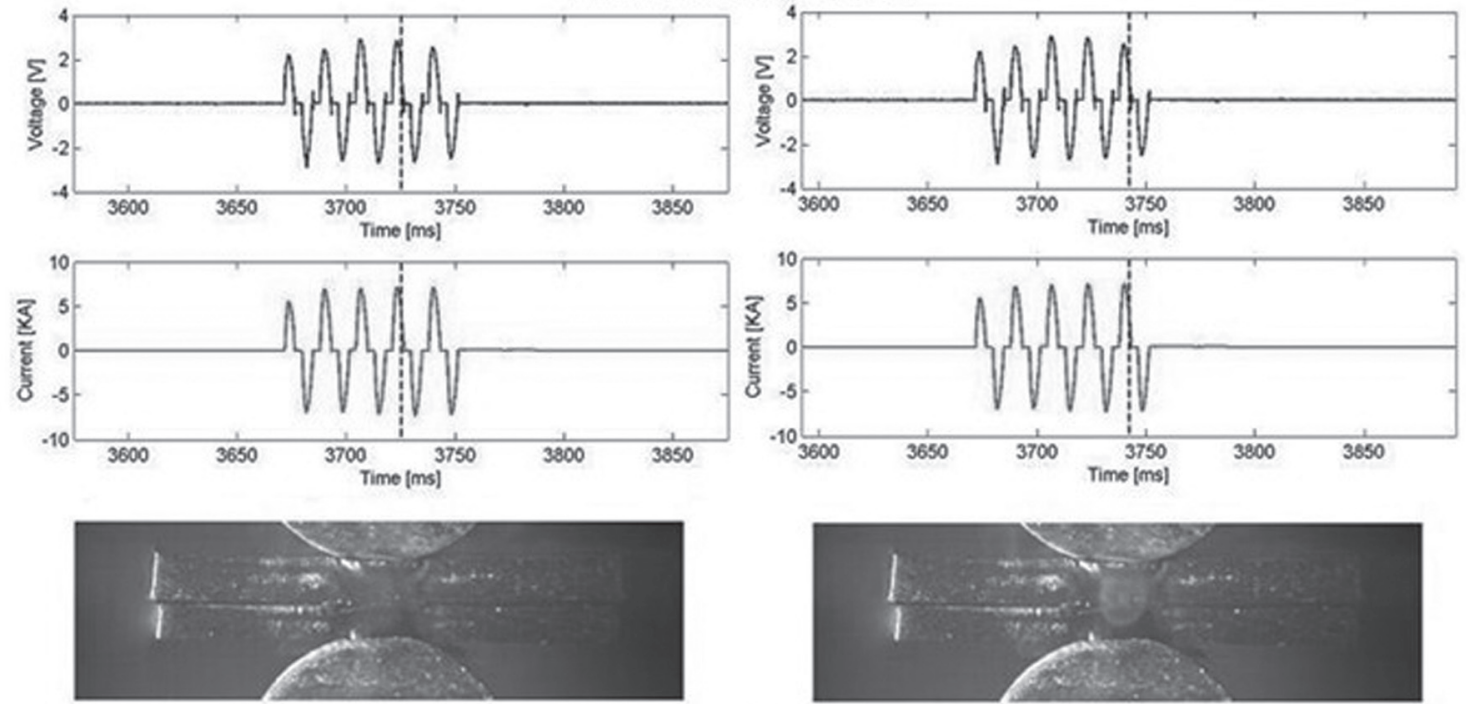

LAPROSOLDA-UFU
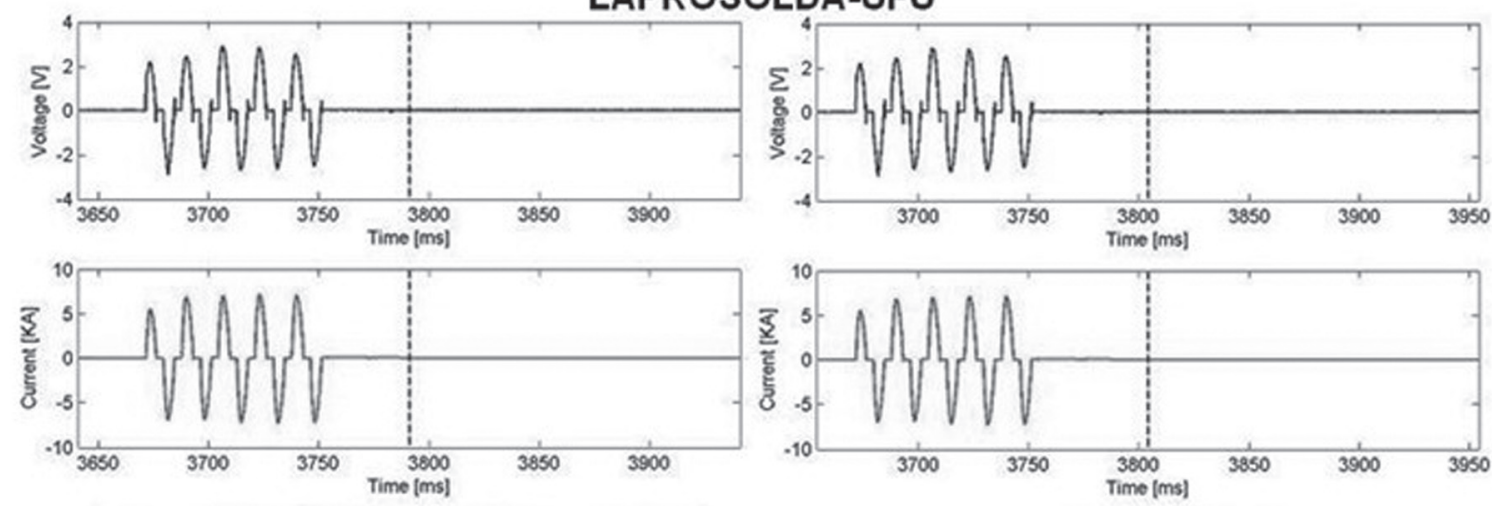

Figura 16. Quadros seqüenciais ilustrando o comportamento da interface chapa-chapa durante a aplicação do "burn-zinc" por 5 ciclos, mas com parâmetros (corrente e pressão) adequados para se obter a queima do revestimento (teste BZ10, realizado com uma corrente de $5 \mathrm{kA}$ com uma regulagem de pressão $\mathrm{P} 1=3,5 \mathrm{em}$ chapas 2,0-2,5 $\mathrm{mm}$ ). 


\section{Avaliação da Eficiência da Técnica de "burn-zinc"}

Evidências de ensaios exploratórios [5], não apresentados neste trabalho, haviam demonstrado que nem para todas as combinações de chapas a soldar, espessura e tipo de galvanização, a técnica "burn-zinc" é vantajosa ou necessária. Houve casos em que, se aplicando a técnica, o tempo para se conseguir um ponto com a mesma dimensão é maior do que quando não se aplica a técnica, como no caso da combinação de chapa espessa (2,0$2,5 \mathrm{~mm}$ ). Assim, para a verificação da eficiência real do uso da técnica "burn-zinc", foram realizados outros testes comparandose soldas completas (usando-se parâmetros adequados para a soldagem em si), com e sem o uso da técnica de "burn-zinc, a partir de uma única parametrização. Como havia sido verificado nos testes exploratórios que para chapas mais espessas o tempo necessário para se conseguir um ponto adequado era grande quando utilizando a queima do zinco, optou-se então, nesta fase por utilizar uma chapa com espessura intermediária (1,2-1,2 $\mathrm{mm})$. Primeiramente, foram realizadas soldagens sem queima de zinco para efeito de comparação. Os parâmetros utilizados estão apresentados na Tabela 2.

Nota-se que os melhores parâmetros para soldar as chapas de 1,2 mm, sem a utilização da técnica do "burn-zinc", foram de 10 ciclos de soldagem com uma corrente de $5 \mathrm{kA}$, conseguindose um ponto com tamanho de 5,6 $\mathrm{mm}$. Quando se utilizou oito ciclos, ou o ponto foi parcialmente formado ou ocorreu expulsão de chapa, não sendo os parâmetros idéias para a combinação das chapas. Definidos os parâmetros idéias para se soldar as chapas de 1,2 $\mathrm{mm}$ sem utilização da técnica da queima do zinco, foram, então, realizados testes para se encontrar os parâmetros otimizados para a realização da técnica de "burn-zinc" para esta combinação de chapas $(1,2 \times 1,2 \mathrm{~mm})$. Inicialmente variaram-se as regulagens da corrente e pressão, mantendo-se o tempo de aplicação do "burn-zinc" em 5 ciclos, como mostra a Tabela 3. Observa-se que se utilizando 5 ciclos com uma corrente de 4 $\mathrm{kA}$, nos três níveis de regulagem de pressão ocorreu o a queima do zinco. Já para as correntes de $5 \mathrm{kA}$ e de $6 \mathrm{kA}$, os parâmetros foram excessivos e ocorreu a colagem das chapas.

Tabela 2. Parâmetros de soldagem e geometria final dos pontos para os testes sem aplicação do ciclo de burn-zinc em chapas com espessuras de 1,2 e 1,2 mm (pressão de 4,0 no equipamento, equivalente a $1619 \mathrm{~N}$ ).

\begin{tabular}{|c|c|c|}
\hline Ciclos & Corrente (kA) & Tamanho do ponto (mm) \\
\hline \multirow{3}{*}{5} & 4 & 0 \\
\cline { 2 - 3 } & 5 & 0 \\
\cline { 2 - 3 } & 6 & 0 \\
\hline \multirow{3}{*}{8} & 4 & 0 \\
\cline { 2 - 3 } & 5 & 3,5 (parcial) \\
\cline { 2 - 3 } & 6 & 5,7 (expulsão) \\
\hline \multirow{3}{*}{10} & 4 & 0 \\
\cline { 2 - 3 } & 5 & $\mathbf{5 , 6}$ \\
\cline { 2 - 3 } & 6 & 5,8 (expulsão) \\
\hline
\end{tabular}

Tamanho mínimo de ponto para aceitabilidade $=4,38 \mathrm{~mm}$
Tabela 3. Parâmetros de soldagem para realizar a queima do zinco com 5 ciclos (chapas de 1,2 e 1,2 mm).

\begin{tabular}{|c|c|c|c|c|}
\hline Teste & $\begin{array}{c}\text { Corrente } \\
{[\mathbf{k A}]}\end{array}$ & $\begin{array}{c}\text { P1-força } \\
{[\mathbf{N}]}\end{array}$ & $\begin{array}{c}\text { Queima } \\
\text { do Zn }\end{array}$ & Observação \\
\hline BZ5-01-2 & 4 & $2,0(736)$ & OK & Boa \\
\hline BZ5-02-2 & 4 & $3,0(1197)$ & OK & Boa \\
\hline BZ5-03-2 & 4 & $4,0(1619)$ & OK & Boa \\
\hline BZ5-04-2 & 5 & $2,0(736)$ & Uniu & - \\
\hline BZ5-05-2 & 5 & $3,0(1197)$ & Uniu & - \\
\hline BZ5-06-2 & 5 & $4,0(1619)$ & Uniu & - \\
\hline BZ5-07-2 & 6 & $2,0(736)$ & Uniu & - \\
\hline BZ5-08-2 & 6 & $3,0(1197)$ & Uniu & - \\
\hline BZ5-09-2 & 6 & $4,0(1619)$ & Uniu & - \\
\hline
\end{tabular}

Porém, para tentar otimizar o procedimento do ponto de vista operacional, optou-se por diminuir o tempo para três ciclos e repetir as condições de teste utilizando a metodologia apresentada no item 2. Os resultados estão apresentados na Tabela 4. Nota-se que agora para uma corrente de $4 \mathrm{kA}$, a queima do zinco ocorreu apenas parcialmente, ou seja, a camada de zinco não foi completamente retirada. Com a corrente de $5 \mathrm{kA}$ na condição de pressão mais baixa $(\mathrm{P} 1=2,0)$ ocorreu a colagem das chapas. Com uma pressão intermediária $(\mathrm{P} 1=3,0)$, ocorreu somente a queima parcial do zinco. Já com a pressão mais alta $(\mathrm{P} 1=5,0)$, o zinco foi queimado e retirado da superfície. Para o último nível de corrente usada (6 kA), na pressão mais baixa $(\mathrm{P} 1=2,0)$ ocorreu a união, o mesmo acontecendo quando se utilizou uma regulagem de pressão de 3,0. Por fim, na regulagem de pressão de 4,0 foi onde se notou a melhor condição para a realização da técnica "burn-zinc", sendo os parâmetros ideais para essa combinação de chapas comprovados pela medição da camada de zinco na região de estudo.

Tabela 4. Parâmetros de soldagem para aplicar a técnica "burnzinc" com 3 ciclos (chapas de 1,2 e 1,2 mm).

\begin{tabular}{|c|c|c|c|c|}
\hline Teste & $\begin{array}{c}\text { Corrente } \\
{[\mathbf{k A}]}\end{array}$ & $\begin{array}{c}\text { P1-força } \\
{[\mathbf{N}]}\end{array}$ & $\begin{array}{c}\text { Queima } \\
\text { do Zn }\end{array}$ & Observação \\
\hline BZ3-01-2 & 4 & 2,0 & OK & Parcial \\
\hline BZ3-02-2 & 4 & 3,0 & OK & Parcial \\
\hline BZ3-03-2 & 4 & 4,0 & OK & Parcial \\
\hline BZ3-04-2 & 5 & 2,0 & Uniu & Expulsão \\
\hline BZ3-05-2 & 5 & 3,0 & OK & Parcial \\
\hline BZ3-06-2 & 5 & 4,0 & OK & Boa \\
\hline BZ3-07-2 & 6 & 2,0 & Uniu & Expulsão \\
\hline BZ3-08-2 & 6 & 3,0 & Uniu & Expulsão \\
\hline BZ5-09-2 & 6 & 4,0 & OK & Ideal \\
\hline
\end{tabular}

Assim, para efeito de comparação com a soldagem sem queima de zinco, foi realizada mais uma série de testes, fixandose a condição de "burn-zinc" ideal para combinação de chapas, 
Tabela 5. Parâmetros de soldagem para os testes com aplicação do ciclo de "burn-zinc" em chapas com espessuras de 1,2 e 1,2 mm.

\begin{tabular}{|c|c|c|c|c|c|c|}
\hline Teste & Corrente $[\mathbf{k A}]$ & Pressão & Corrente $[\mathrm{kA}]$ & Pressão & $\begin{array}{c}\text { Espera entre } \\
\text { impulsos }\end{array}$ & $\begin{array}{c}\text { Tam. } \\
\text { Ponto }(\mathbf{m m})(*)\end{array}$ \\
\hline & \multicolumn{2}{|c|}{ Burn-Zinc 3 ciclos } & \multicolumn{2}{|c|}{ Solda 10 ciclos } & & \\
\hline BZ310-01 & 6 & 4 & 5 & 4 & 3 & 5,8 \\
\hline BZ310-02 & 6 & 4 & 5 & 4 & 5 & 4,4 \\
\hline \multirow[t]{2}{*}{ BZ310-03 } & 6 & 4 & 5 & 4 & 10 & 4,6 \\
\hline & \multicolumn{2}{|c|}{ Burn-Zinc 3 ciclos } & \multicolumn{2}{|c|}{ Solda 8 ciclos } & & \\
\hline BZ38-1 & 6 & 4 & 5 & 4 & 3 & 5,5 \\
\hline BZ38-2 & 6 & 4 & 5 & 4 & 5 & 4,1 \\
\hline \multirow[t]{2}{*}{ BZ38-3 } & 6 & 4 & 5 & 4 & 10 & 0 \\
\hline & \multicolumn{2}{|c|}{ Burn-Zinc 3 ciclos } & \multicolumn{2}{|c|}{ Solda 5 ciclos } & & \\
\hline BZ35-01 & 6 & 4 & 5 & 4 & 3 & 0 \\
\hline BZ35-02 & 6 & 4 & 5 & 4 & 5 & 0 \\
\hline BZ35-03 & 6 & 4 & 5 & 4 & 10 & 0 \\
\hline
\end{tabular}

* Tamanho mínimo de ponto para aceitabilidade $=4,4 \mathrm{~mm}$

ou seja, tempo de três ciclos com a corrente de $6 \mathrm{kA}$ e uma regulagem de pressão de 4,0. O tempo de corrente, ou seja, o tempo regulado para passagem de corrente durante o ciclo de soldagem após os três ciclos do "burn-zinc" foi variado em 10, 8 e 5 ciclos. Variou-se também o tempo entre os ciclos do "burnzinc" e os ciclos de soldagem, chamado de tempo de espera. Foram utilizados 3, 5 e 10 ciclos entre eles. A Tabela 5 resume os parâmetros dessa fase de testes. Observa-se que os parâmetros ideais (em destaque na tabela), para a combinação de chapas ensaiadas, foram de oito ciclos e uma espera de três ciclos entre o "burn-zinc" e a soldagem. Quando comparado com a soldagem sem a técnica da queima do zinco, o tempo de corrente caiu para 8 ciclos em relação aos 10 ciclos necessários para ocorrer a soldagem. Porém no total foram gastos 14 ciclos para se completar todo o processo de soldagem. Esses 4 ciclos a mais necessários para a utilização da técnica do "burn-zinc" talvez possam ser justificáveis por um possível ganho de qualidade no final da soldagem, podendo diminuir o número de pontos refugados.

Para uma melhor visualização do efeito da técnica de "burn-zinc", foi filmado o procedimento de soldagem, primeiramente somente com a solda sem a queima do zinco, Figura 17, e, posteriormente, a soldagem com o uso do "burnzinc", utilizando-se os parâmetros idéias encontrados, Figura 18. Observa-se que logo após os 3 ciclos de "burn-zinc" aparece uma fumaça esbranquiçada saindo da região onde se formará o ponto de solda, caracterizando a evaporação do zinco presente na região de formação do ponto de solda, confirmando a eficiência da técnica.

É importante destacar que, mesmo que o enfoque aqui tenha sido dado sobre a redução do tempo de soldagem pela otimização que se pode levar pelo uso da técnica de "burn-zinc", outras vantagens poderiam advir do uso da técnica, como aumento da vida útil dos eletrodos. Este ponto seria tópico de um estudo mais compreensível.

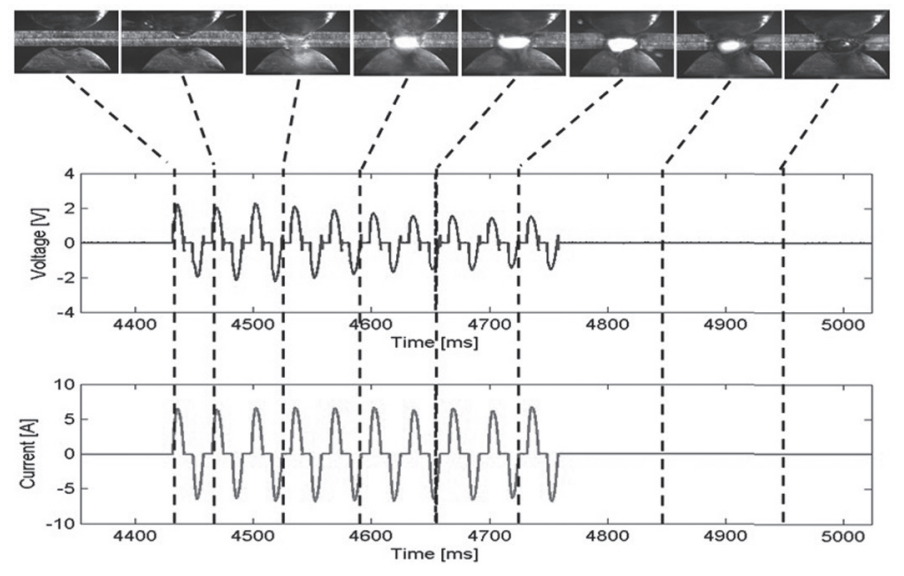

Figura 17. Quadros seqüenciais ilustrando o comportamento da interface chapa-chapa durante a soldagem (10 ciclos, $5 \mathrm{kA} \mathrm{e}$ pressão de 4,0) sem uso de "burn-zinc".

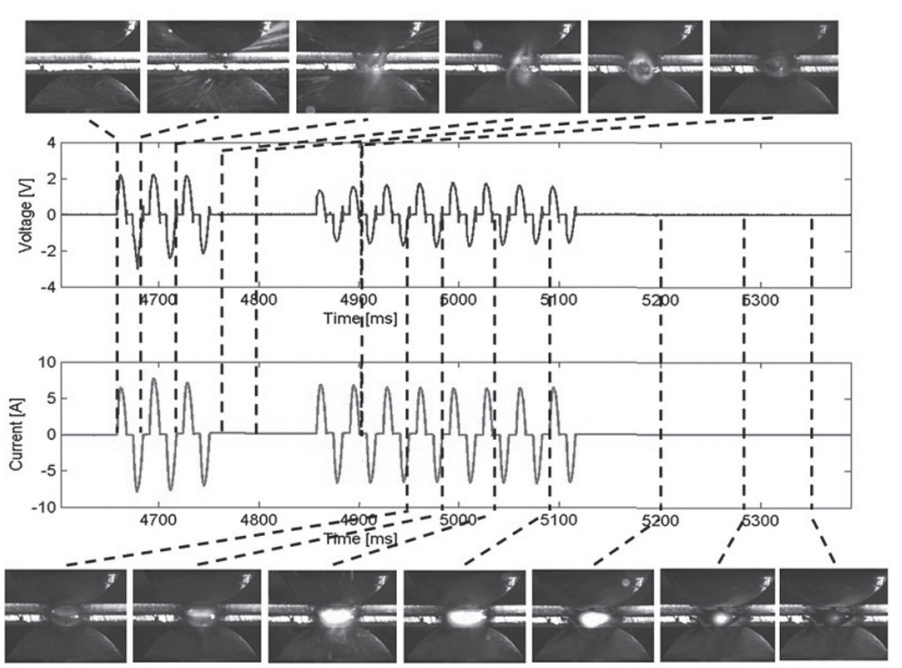

Figura 18. Quadros seqüenciais ilustrando o comportamento da interface chapa-chapa durante a. soldagem com uso de "burnzinc" (teste BZ38-1). 


\section{Conclusões}

A utilização da técnica "burn-zinc" pode ser uma importante ferramenta nas soldagens de chapas com revestimento de zinco (galvanizada). Entretanto, a aplicação da técnica deve ser feita com critério. Primeiro, tem de se verificar o envelope de parâmetros que garanta o efeito real de queima do zinco para cada condição de soldagem (tipo e espessura de chapa). Em seguida, tem de se verificar se a eficiência da técnica se confirma para esta dada condição (o grau da eficácia do "burn-zinc" vai depender de várias variáveis presentes no processo, principalmente a espessura e tipo de galvanização das chapas a serem soldadas e do tempo entre o impulso para o "burn-zinc" e a soldagem propriamente dita). Terceiro, avaliar se outros benefícios, não cobertos pela metodologia proposta, como aumento da vida útil dos eletrodos se confirmaria e aumentaria o alcance do uso da técnica. Os procedimentos experimentais para essas verificações descritos acima mostraram como eficientes para a verificação e parametrização da técnica "burn-zinc". Naturalmente outros resultados podem ser obtidos, caso se use, por exemplo, maior corrente para a técnica "burn-zinc" (se não houver limitação do equipamento).

\section{Agradecimentos}

Os autores gostariam de agradecer aos professores do Laprosolda, Prof. Louriel Vilarinho e Prof. Valtair Antônio Ferraresi, pelas sugestões e contribuições durante a realização do trabalho. Também agradecer à Fapemig, ao CNPq e ao IFM, pela infra-estrutura laboratorial e bolsa de pesquisa, e à CAPES (bolsa de estudo de um dos autores).

\section{Referências Bibliográficas}

[1] MatWeb - Material Property Data <http://www.matweb. com>. Acesso em: 18 Jul. 2007.

[2] GUEDES, J.B., GONÇALVES, R.A. \& SCOTTI, A., Avaliação de Desgaste de Eletrodos em Solda a Ponto por Resistência de Chapas Galvanizadas, Soldagem \& Inspeção, 10 (2), Abr/Mai 2005, pp. 72-78 (ISSN 0104-9224).

[3] RWMA - Resistance Welding Manual, Resistance Welder Manufacturing Association. U.S.A., 4th Ed., Nov. 1989. 443 p. [4] VILARINHO, L. O., VARGAS, J. E. A., WOLFF, M. A., ALFARO, S. C. A., 2006, "Study of Resistance Spot Welding Process by Using Synchronized High Speed Filming”, Soldagem \& Inspeção, Vol. 11, No 3, Jul/Set. 2006.

[5] NASCIMENTO, V.C. Seleção de Parâmetros de Soldagem a Ponto por Resistência, Baseado na Medição da Resistência Elétrica entre Chapas. Tese de Mestrado, Universidade Federal de Uberlândia, Uberlândia. 2008. 130p.

[6] AWS/SAE D8.9M. Recommended Practices for Test Methods for Evaluating the Resistance Spot Welding Behavior of Automotive Sheet Steel Materials. International Standard Book Number: 0-87171-672-0. 2002. American Welding Society. 550 N. W. LeJeune Road, Miami, Florida 33126. Printed in the U.S.A. 2002. 